\title{
Antibiotic resistance genes in food and gut (non-pathogenic) bacteria. Bad genes in good bugs
}

\author{
Henk Aarts ${ }^{1}$ and Abelardo Margolles ${ }^{2 *}$ \\ Department of Foodborne Infections, Centre for Zoonoses and Environmental Microbiology, National Institute for Public Health and the Environment, Bilthoven, \\ Netherlands \\ ${ }^{2}$ Department of Microbiology and Biochemistry of Dairy Products, Dairy Research Institute, Spanish National Research Council, Villaviciosa, Asturias, Spain \\ *Correspondence: amargolles@ipla.csic.es
}

Edited and reviewed by:

Joanne Chee-Sanford, U.S. Department of Agriculture-Agricultural Research Service, USA

Keywords: probiotics, Lactobacillus, bifidobacterium, commensals, antibiotic resistance genes, food, intestinal

Some ecosystems are inhabited by an extraordinarily dense population of microbes, such as fermented foods. Their microbial load can reach higher than one billion microorganisms per gram, although the bacterial diversity is normally low due to the prevalence of a few strains which rapidly adapt to a quickly changing environment. Even higher microbial numbers can be present along the human intestinal tract; however in this case the bacterial diversity is much higher comprising hundreds of different species. The large majority of bacteria inhabiting these niches is commensal and does not suppose a health risk, i.e., lactic acid bacteria in dairy fermentations or bifidobacteria in the gut of breast-fed infants. However, the close proximity of bacterial cells in such a densely populated habitats could favor the transfer of genetic material containing antibiotic resistance (AR) genes to potential pathogens, and as such could threaten human health.

Two manuscripts included in this Research Topic review current literature on AR genes present in Lactic Acid Bacteria and bifidobacteria, species which are currently used as probiotics in animal and human nutrition, or as starter cultures in fermented foods. Devirgiliis et al. (2013) report an update on AR in foodborne Lactobacillus and Lactococcus species, two genera of Lactic Acid bacteria commonly used for the fermentation of meat, milk, and vegetables. Representatives of these species are mostly non-pathogenic, but a large variety of transmissible AR genes have been identified and characterized in them. For example transfer of tetracycline resistance genes from Lactococcus lactis to Enterococcus faecalis was demonstrated. Furthermore, different Lactobacillus species were able to transfer erythromycin and tetracycline resistance genes to E. faecalis, indicating a potential risk of using Lactic Acid Bacteria starters that have not been tested for the absence of AR genes. On the other hand, the ubiquity of tet $(\mathrm{W})$ gene in Bifidobacterium species is highlighted in the mini review of Gueimonde et al. (2013). Bifidobacterium can be the dominant bacterial population in breast-milk babies, and some species such as $B$. animalis subsp. lactis are extensively used in functional foods. Even though there is no experimental evidence of the transfer of AR genes from bifidobacteria to pathogenic bacteria, the transfer of tet (W) genes among Bifidobacterium species has been demonstrated.

The impact of multidrug resistant Escherichia coli, belonging to the group of commensal enterobacteria, isolated from animals has been tackled in this issue by Szmolka and Nagy (2013). E. coli has a plethora of different AR mechanisms, including efflux pumps and mobile resistance elements that allow them to adapt to environments challenged by antibiotics. In food animals, these microorganisms are a source for the spread of AR genes throughout the entire food chain, representing a public health issue. Machado et al. (2013) highlighted the role of members of the family Enterobacteriacea in the spread of AR. They investigated the extended-spectrum beta-lactamase (ESBL)producing Enterobacteriaceae in fecal samples of healthy humans and the presence of sulfonamide resistance genes. While ESBLproducing isolates were found in $1.8 \%$ of the samples, sul genes were found in a very high proportion of the isolates that were sulfonamide resistant. The sul genes were often located in integrons, reinforcing the role of Enterobacteriaceae members as potential transmitters of AR genes.

Rolain (2013) and Penders et al. (2013) emphasized the potential of food and human gut as reservoirs of AR genes. Rolain compiled the sources of $\mathrm{AR}$ in human pathogens, i.e., food animals, aquaculture, fruits, and vegetables. Current literature support that these sources are a major factor contributing to the emergence of AR bacteria. Penders and coworkers paid special attention to the so called resistome, the whole set of AR genes found in a specific niche. They focused their review on the resistome analysis of the human gut. This has been possible thanks to the advent of next generation sequencing techniques and to the abundant metagenomic studies performed in human fecal samples. Different approaches have been used to unravel the gut resistome, such as targeted PCR-based metagenomics, functional metagenomics and sequence-based metagenomics, revealing the presence of novel genes in unculturable bacteria. However, these techniques are now starting to emerge and their application in clinic is still far from being implemented.

Djordjevic et al. (2013) offer an overview of the importance of mobile elements in spreading AR between humans, animals and soil. Commensal bacteria can facilitate transfer and amplify the reservoir of AR genes in these niches, and mobile elements seem to play a pivotal role in these processes.

In summary, the articles within this Research Topic aim to raise interest in scientists working on AR to reflect on the potential risk of the huge reservoir of AR genes that are present 
in various ecosystems, like those present in the human body and food. The food and gut resistomes are mainly localized in beneficial/commensal bacteria, however environmental and physiological factors could exert undesirable effects like the mobilization of these genes to be transferred into non-desirable bacteria, with the corresponding risk for human health. Thus, scientific strategies oriented to know the real risk of harboring a high AR gene load in foods and ultimately in the human gut, are urgently needed and deserve the attention of public regulatory agencies and policy makers.

\section{REFERENCES}

Devirgiliis, C., Zinno, P., and Perozzi, G. (2013). Update on antibiotic resistance in foodborne Lactobacillus and Lactococcus species. Front. Microbiol. 4:301. doi: 10.3389/fmicb.2013.00301

Djordjevic, S. P., Stokes, H. W., and Chowdhury, P. R. (2013). Mobile elements, zoonotic pathogens and commensal bacteria: conduits for the delivery of resistance genes into humans, production animals and soil microbiota. Front. Microbiol. 4:86. doi: 10.3389/fmicb.2013.00086

Gueimonde, M., Sánchez, B., de los Reyes-Gavilán, C. G., and Margolles, A. (2013). Antibiotic resistance in probiotic bacteria. Front. Microbiol. 4:202. doi: 10.3389/fmicb.2013.00202

Machado, E., Coque, T. M., Cantón, R., Sousa, J. C., and Peixe, L. (2013). Commensal Enterobacteriaceae as reservoirs of extended-spectrum betalactamases, integrons, and sul genes in Portugal. Front. Microbiol. 4:80. doi: $10.3389 /$ fmicb. 2013.00080
Penders, J., Stobberingh, E. E., Savelkoul, P. H., and Wolffs, P. F. (2013). The human microbiome as a reservoir of antimicrobial resistance. Front. Microbiol. 4:87. doi: 10.3389/fmicb.2013.00087

Rolain, J. M. (2013). Food and human gut as reservoirs of transferable antibiotic resistance encoding genes. Front. Microbiol. 4:173. doi: $10.3389 /$ fmicb. 2013.00173

Szmolka, A., and Nagy, B. (2013). Multidrug resistant commensal Escherichia coli in animals and its impact for public health. Front. Microbiol. 4:258. doi: 10.3389/fmicb.2013.00258

Conflict of Interest Statement: The authors declare that the research was conducted in the absence of any commercial or financial relationships that could be construed as a potential conflict of interest.

Received: 20 November 2014; accepted: 11 December 2014; published online: 09 January 2015.

Citation: Aarts $H$ and Margolles A (2015) Antibiotic resistance genes in food and gut (non-pathogenic) bacteria. Bad genes in good bugs. Front. Microbiol. 5:754. doi: 10.3389/fmicb.2014.00754

This article was submitted to Antimicrobials, Resistance and Chemotherapy, a section of the journal Frontiers in Microbiology.

Copyright (c) 2015 Aarts and Margolles. This is an open-access article distributed under the terms of the Creative Commons Attribution License (CC BY). The use, distribution or reproduction in other forums is permitted, provided the original author(s) or licensor are credited and that the original publication in this journal is cited, in accordance with accepted academic practice. No use, distribution or reproduction is permitted which does not comply with these terms. 